\title{
Construct validity of the Moral Development Scale for Professionals (MDSP)
}

This article was published in the following Dove Press journal:

Journal of Multidisciplinary Healthcare

24 May 2011

Number of times this article has been viewed

\author{
Olle Söderhamn ${ }^{1,2}$ \\ John Olav Bjørnestad' \\ Anne Skisland' \\ Christina Cliffordson ${ }^{2}$ \\ 'Faculty of Health and Sport Sciences, \\ University of Agder, Grimstad and \\ Kristiansand, Norway; ${ }^{2}$ Department \\ of Nursing, Health and Culture, \\ University West, Trollhättan, Sweden
}

Correspondence: Olle Söderhamn Professor in Nursing Science, Department of Health and Nursing Sciences, Faculty of Health and Sport Sciences, University of Agder, PO Box 509, NO-4898 Grimstad, Norway

Tel +4737233797

Email olle.soderhamn@uia.no

\begin{abstract}
The aim of this study was to investigate the construct validity of the Moral Development Scale for Professionals (MDSP) using structural equation modeling. The instrument is a 12-item self-report instrument, developed in the Scandinavian cultural context and based on Kohlberg's theory. A hypothesized simplex structure model underlying the MDSP was tested through structural equation modeling. Validity was also tested as the proportion of respondents older than 20 years that reached the highest moral level, which according to the theory should be small. A convenience sample of 339 nursing students with a mean age of 25.3 years participated. Results confirmed the simplex model structure, indicating that MDSP reflects a moral construct empirically organized from low to high. A minority of respondents $>20$ years of age (13.5\%) scored more than $80 \%$ on the highest moral level. The findings support the construct validity of the MDSP and the stages and levels in Kohlberg's theory.
\end{abstract}

Keywords: Kohlberg, scale testing, simplex structure model, structural equation modeling

\section{Introduction}

Many moral psychologists today accept that there are two types of moral reasoning focusing on Lawrence Kohlberg's justice and Carol Gilligan's care. ${ }^{1}$ Kohlberg elaborated the cognitive approach to moral development and formulated his moral stage theory, ${ }^{2,3}$ which came to be very influential in the field for many years. ${ }^{4}$ Gilligan's criticism ${ }^{5}$ of Kohlberg's theory was not only a critique of the absence of a gender-related focus but also of the scientific approach and methods. The cognitive view of moral development denotes that the logic of a person's reason influences moral behavior in accordance with his or her judgement. ${ }^{4}$ A more relational approach to morality is proposed in the care oriented view by Gilligan, ${ }^{5}$ who also argues that this is more representative of the moral experience of women. ${ }^{4,5}$ However, the two views of moral reasoning may be considered as complementary to each other with Gilligan's work more regarded as an expansion of Kohlberg's theory than merely a critique. ${ }^{1,6}$

Choosing a cognitive approach in line with Kohlberg's theory means that moral function is considered to contain not only thinking about issues of right or wrong in social relationships, but also emotions. Furthermore, it implies that the way people conceptualize these issues are grounded in their understanding of justice, rights, fairness, and the welfare of other individuals. Moral awareness and knowledge are formed in childhood and undergo developmental transformations during life. ${ }^{7}$

Although it has been much criticized over the years, Kohlberg's theory is still important in research on moral development. Rest et $\mathrm{al}^{8}$ have launched a fruitful 
neo-Kohlbergian approach that has guided a number of empirical studies, which have given strong support to Kohlberg's theory. The core ideas in this research are the emphasis on cognition, the individual's construction of moral epistemology, the moral judgment development evolving from simpler ideas to more complex ones, and the individual's growing awareness of the importance of society and of how people interrelate through laws, rules, institutions, and roles.

Despite much strength in contemporary critical work, Arnold $^{4}$ argues that the fundamental place of reason in morality cannot be dismissed, and should be investigated further and clarified in future empirical studies. To be able to investigate moral development among individuals according to Kohlberg's theory within a quantitative research paradigm, reliable and valid instruments are essential. In order to study moral development according to this theory in a culturally coherent way in Scandinavia, an instrument, the Moral Development Scale for Professionals (MDSP) ${ }^{9}$ has been developed and initially tested for reliability and validity in Norway, where a number of items following the conventional and postconventional levels in the theory ${ }^{2,3}$ were developed. Although sufficient and fairly sound psychometric properties were shown for the new instrument, ${ }^{9}$ further testing is needed, especially the issue of construct validity tested with structural equation modeling (SEM), because the instrument is grounded in a theory.

The aim of this study was to investigate construct validity of the MDSP with SEM.

\section{The Moral Development Scale for Professionals}

The MDSP is based on Lawrence Kohlberg's theory of moral development, ${ }^{2,3}$ which proposes that individuals pass through moral stages from the concrete to the abstract. The scale has been developed with the aim of measuring moral development among adults, who can be expected to have reached the upper levels of Kohlberg's stages of moral development, ie, the conventional and postconventional levels. ${ }^{9}$

Kohlberg's theory suggests that moral development can be conceptualized along a continuum ranging from low and concrete to high and abstract levels: 1) the preconventional level, 2) the conventional level, and 3) the postconventional level. At each level there are 2 stages. Most children under 9 years of age are on the preconventional level. At the first stage on this moral level (stage 1), the individual cannot recognize the interests of other people fully and does not consider them. The individual may be viewed as a selfish actor, and moral judgement is linked to physical consequences. To avoid punishment is the reason for doing right as well as the superior power of authorities. At the second stage (stage 2), the perspective is more individualistic, and one's own interests and needs guide the right actions in a world where other individuals also have their interests and needs., ${ }^{2,3}$

Most adolescents and adults in Western society have reached the conventional level of moral development. The first stage (stage 3 ) is characterized by the individual's perspective in relationships with other people. Individual interests are not as important anymore, and shared feelings, expectations of other people, and agreements between individuals have become increasingly important. There is a wish to please and help others and to be approved by other people, ie, to be a good girl or boy. At stage 4, the individual is guided by the system that defines rules and laws and by the earned expectations of others. Law and order are central to this stage. ${ }^{2,3}$

The postconventional level is typified by moral values that are in conformity with the self and with sharable and shared rights, duties, and standards. This level is reached only by a minority of adults after the age of 20 years $^{2,3}$ or even after 30 years. ${ }^{10}$ At the first stage on this level (stage 5), the rational individual is well aware of rights and values prior to social attachments and contracts. That legal and moral points sometimes may diverge and be in conflict with each other is recognized. Provision of the greatest good to the greatest number of people is also central to this stage. Right and wrong are constituted by the norms of the majority in society. At the last stage (stage 6), conscience and universal ethical principles are in focus. Human beings are ends in themselves, self-chosen ethical principles are followed, and the nature of morality is recognized by the rational individual. ${ }^{2,3}$

In order to measure moral development among adults, MDSP has been constructed. Since the preconventional level in Kohlberg's theory reflects early stages in the development it was not incorporated in the instrument. The conventional level, with its 2 stages focusing on moral thinking in the individual's family, among friends, and in society in general, was included in the construction of items that mirror this view. The perspective of the postconventional level, with the 2 stages, 5 and 6, reflecting universal ethical principles and basic democratic rights and values, was also incorporated in the items. ${ }^{9}$

The summated self-report instrument was developed in the Norwegian language in Norway. Thirty-two items reflecting the 4 stages of moral development at the conventional and postconventional levels, 8 items for each stage, were 
formulated in a Likert-type format. After different actions to test the appropriateness of the items, an instrument with 12 items was finally chosen to be suitable to have in the instrument. ${ }^{9}$ These actions were implemented with data from different study groups. Fifty-three students scrutinized the wording of the items. A group of 183 students answered the scale and item-to-item correlations were computed. Data from a study group of 326 students were used for further reduction of the items by means of a factor analysis (principal component analysis with varimax rotation and Kaiser Normalization) and item-to-item correlations. Item reduction followed the recommendations formulated by Streiner and Norman. ${ }^{11}$

Validity of the final instrument was supported by the fact that there was a significant difference between student groups with an expected higher score and students with an expected lower score, respectively. Validity was also partly supported by a factor analysis that explained $51 \%$ of the variances with a logical 4-factor solution. ${ }^{9}$

Reliability assessed as internal consistency with the Cronbach's alpha coefficient reached a value of 0.67 in the study group of 326 students. ${ }^{9}$ Since a value of 0.70 is considered to be sufficient for group level comparisons, the reliability of MDSP should be considered as acceptable in the initial testing and development procedures. The instrument is built up of items that to some degree are causal indicators and, therefore, high internal consistency is not as critical. ${ }^{11}$ Causal indicators are in this particular context items that lead to behavior that reflect a particular stage or level in Kohlberg's theory.

The final instrument has 12 Likert-type items ranging from 1 ("not agree at all") to 5 ("agree completely"), which yields a total sum between 12 and 60. A higher score indicates a higher degree of moral development. The intention of MDSP has been to provide a scale that can be used to evaluate moral development among, for example, students and professionals for whom it is essential to have a well developed ability for moral behavior, ethical thinking, and decision making.

Although indications of validity have been shown in the initial development and testing procedures, ${ }^{9}$ there is a need for testing with SEM.

\section{Methods}

\section{Study group}

A convenience sample of a total of 339 nursing students at a university college in Norway was recruited for the study during 2 different years. The request to participate in the study was made in the classroom during ethics education. Mean age in the study group was 25.3 years, ranging from 18 to 53 years. Eighteen males $(5.3 \%)$ were present in the study group, and there was no difference in age between males and females when $t$ tested for independent samples (2-tailed probability)

\section{Analyses}

Validity of the scale was assessed as construct validity and first tested through SEM by the use of simple structure models. ${ }^{12}$ The program Mplus version 3.13 was used for the SEM analyses ${ }^{13}$ within the STREAMS modeling environment for specifying, estimating, and evaluating the models. ${ }^{14}$ Model fit was measured with the root mean square error of approximation (RMSEA) and chi-square tests. A value of RMSEA of about 0.05 represents a close fit of the model, although values up to 0.08 may be acceptable. ${ }^{15}$ When chisquare tests are used in this context, model fit is ideal when there is no difference between data and the model.

A 1-factor model was first tested with all items of MDSP influencing 1 single latent variable. A hypothesized simplex structure model, with 4 latent variables, was tested in a second step. In this model, items representing the intended Kohlberg stages 3, 4, 5, and 6, respectively, influenced the 4 latent variables.

Based on results from the 4-factor model, it was hypothesized that the final model consisted of 3 latent variables, where 2 of them were representing the 2 stages ( 3 and 4 , respectively) on the conventional level and 1 the whole postconventional moral level (stages 5 and 6).

Internal consistency of the latent variables in the final model, as well as the internal consistency of the whole scale, was assessed with the Cronbach's alpha coefficient. ${ }^{16}$

According to Kohlberg's theory of moral development, only a minority of individuals reach the postconventional level after the age of 20 years. ${ }^{2,3}$ Construct validity was tested through investigation of how large a proportion of the respondents older than 20 years achieved a high score, ie, a total sum score $\geq 24$, on the items at stage 5 and stage 6 .

\section{Ethical considerations}

Written permission for doing the research with students as respondents was obtained from the current leaders at the university college. Oral information and the option to withdraw from the data collection were given to the respondents when the questionnaires were handed out to them. Participation was regarded as informed consent. Data were treated with confidentiality, and the same ethical principles that guide clinical research 
were applied, ${ }^{17}$ as well as the intentions of the Declaration of Helsinki. ${ }^{18}$ Since no health information was requested from the respondents, no formal approval from the regional committee for research ethics needed to be obtained.

\section{Results}

A 1-factor model of moral development showed a close goodness-of-fit with RMSEA $=0.039$, indicating that 1 single concept is reflected in the model. Chi-square was 81.71 $(d f=54), P<0.01$.

In the second step of the investigation, a 4-factor simplex model was hypothesized and tested. This model is displayed in Figure 1. This model also showed a close goodness-of-fit with RMSEA $=0.042$ and chi-square $81.03(d f=51), P<$ 0.00 . Here, stage 3 on the conventional level explained $72 \%$ of the variances in 4 . Stage 4 explained $81 \%$ of the variances in 5 on the postconventional level. However, stage 5 explained $100 \%$ of the variances in 6 , which presumably means that information is lacking at the postconventional level, where only 2 items represent the final stage. This result means that the 2 stages on the postconventional level cannot be separated from each other in the study group.

The final 3-factor model showed a close goodness-offit with RMSEA $=0.041$ and chi-square $81.12(d f=52)$, $P<0.01$. Standardized factor loadings for this model are displayed in Table 1. The Cronbach's alpha coefficient for the whole scale reached a value of 0.64 .

No respondent reached the maximum score total, ie, 30 , on the postconventional level. The highest value was 28 , which was obtained by 2 individuals. A total number of 27 individuals (13.5\%) above 20 years of age reached a value $\geq 24$ ( $80 \%$ of maximum score) on this moral level.

\section{Discussion}

The importance of reliable and valid instruments in research cannot be emphasized enough. Valid instruments that are grounded in theory can be used not only to measure phenomena within the theory in question. But they may also be a means to test the theory itself. The aim of this study was to investigate construct validity of the MDSP with SEM.

Many instruments are built on Kohlberg's theory of moral development, ${ }^{2,3}$ which have primarily been used in studies in the English speaking world. ${ }^{6,19}$ This article focuses validity testing of MDSP, developed in the Scandinavian cultural context, with the aim of measuring moral development among adults, who are presumed to have reached the higher levels of moral development. ${ }^{9}$ MDSP differs a lot from many other similar instruments. One such well known instrument is the Defining Issues Test, ${ }^{20}$ also grounded in Kohlberg's theory of moral development, ${ }^{2,3}$ although it assumes some changes in the original thinking. ${ }^{21}$ That instrument is time consuming to use because of its format, with cases yet to be discussed. This complicated type of instrument is not suitable for larger screening studies. MDSP is designed to be quite easy to use and not very time consuming for the respondents to answer.

Because the stages as well as the moral levels are conceptualized along a continuum from low to high in the theory that underlies the instrument, a simplex structure model tested through structural equation modelling was suitable for testing the relationship between the stages and levels. A convenience sample of nursing students participated in the study.

It was not possible to separate the two stages at the postconventional level (stage 5 and 6) in the simplex structure model that was tested, probably because only 2 items reflected the highest stage. This is a limitation of the instrument, but in the construction phase only 2 items at this stage had sufficient psychometric properties to be retained. It may also be logical that the two highest stages are difficult to separate, since the dialectical joining of judgement-experience processes with reflective claims of others at stage 5 may continuously develop into a personal judgement at stage 6 , informed by

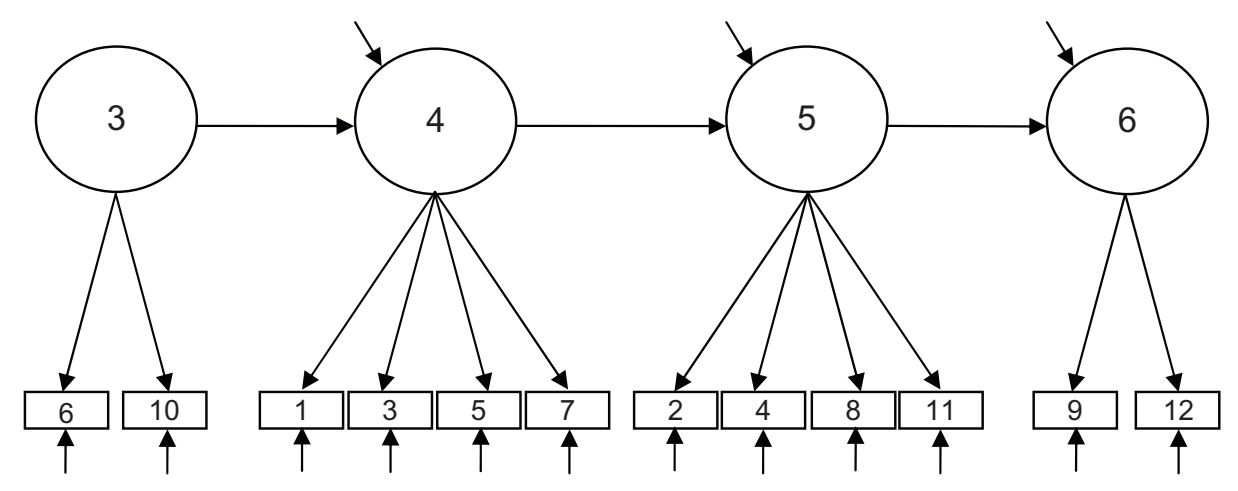

Figure I The 4-factor simplex model of moral development. 
Table I Standardized factor loadings of the three-factor simplex model of moral development

\begin{tabular}{|c|c|c|c|c|c|c|c|}
\hline Variable & Item content & $\begin{array}{l}\text { Intended } \\
\text { Kohlberg- } \\
\text { stage }\end{array}$ & $\begin{array}{l}\text { Conventional } \\
\text { level } \\
\text { stage } 3\end{array}$ & $\begin{array}{l}\text { Conventional } \\
\text { level } \\
\text { stage } 4\end{array}$ & $\begin{array}{l}\text { Postconventional } \\
\text { level } \\
\text { stages } 5 \text { and } 6\end{array}$ & $t$-test & $P$ values \\
\hline Item I & $\begin{array}{l}\text { To meet with expectations } \\
\text { from others has its own value }\end{array}$ & 4 & & 0.38 & & 5.26 & 0.000 \\
\hline Item 2 & $\begin{array}{l}\text { Important to listen to what } \\
\text { people mean in moral issues }\end{array}$ & 5 & & & 0.42 & 5.26 & 0.000 \\
\hline Item 3 & $\begin{array}{l}\text { Right behavior consists of } \\
\text { doing one's duties }\end{array}$ & 4 & & 0.48 & & 6.33 & 0.000 \\
\hline Item 4 & The majority is seldom wrong & 5 & & & 0.36 & 4.95 & 0.000 \\
\hline Item 5 & $\begin{array}{l}\text { Immoral conduct breaks } \\
\text { established laws and rules }\end{array}$ & 4 & & 0.42 & & 6.66 & 0.000 \\
\hline Item 6 & $\begin{array}{l}\text { Consideration and kindness } \\
\text { most important values in a } \\
\text { community }\end{array}$ & 3 & 0.30 & & & 3.29 & 0.001 \\
\hline Item 7 & $\begin{array}{l}\text { A value in itself to treat } \\
\text { authorities with respect }\end{array}$ & 4 & & 0.45 & & 6.95 & 0.000 \\
\hline Item 8 & $\begin{array}{l}\text { Reasonable to listen to what } \\
\text { most people mean is right or } \\
\text { wrong }\end{array}$ & 5 & & & 0.44 & 4.87 & 0.000 \\
\hline Item 9 & $\begin{array}{l}\text { A good value valid for all } \\
\text { people }\end{array}$ & 6 & & & 0.30 & 3.87 & 0.000 \\
\hline Item 10 & $\begin{array}{l}\text { A necessary condition for an } \\
\text { action to be good is a good } \\
\text { thought behind }\end{array}$ & 3 & 0.41 & & & 3.87 & 0.000 \\
\hline Item II & $\begin{array}{l}\text { Usually possible to reach } \\
\text { consensus in moral issues }\end{array}$ & 5 & & & 0.34 & 4.84 & 0.000 \\
\hline Item 12 & $\begin{array}{l}\text { Good moral rules must be } \\
\text { able to be put in a context }\end{array}$ & 6 & & & 0.35 & 3.87 & 0.000 \\
\hline $\begin{array}{l}\text { Cronbach's } \\
\text { alpha }\end{array}$ & & & 0.20 & 0.47 & 0.47 & & \\
\hline
\end{tabular}

the experiences of all previous stages. It is also possible not enough students had reached stage 6 , which seldom occurs before 40 years of age.$^{10}$ However, a structure with both levels of the postconventional stage merged into 1 single latent variable gave a model with a close goodness-of-fit. Although the chi-square tests had significant values, which often is the case, there is a close goodness-of-fit for all 3 models. The simplex structure of the model obtained supports construct validity of the instrument. It also corroborates Kohlberg's moral stage theory. ${ }^{2,3}$ However, Cronbach's alpha coefficients of the factors are too low to be used as separate subscales. The alpha value for the whole scale was not very high either, but close to the value reported before, ${ }^{9}$ and 0.70 is considered adequate for group level comparisons. The reason for this borderline value is probably that some of the items are causal factors. ${ }^{11}$ Another possible reason is that the items of MDSP both reflect what Rest et $\mathrm{al}^{8}$ call macromorality and micromorality, respectively. Kohlberg's theory ${ }^{2,3}$ primarily addresses issues concerning macromorality, ie, issues related to formal structures in society such as laws, institutions, and general practices. Micromorality, on the other hand, concerns developing relationships with particular others and the creation of personal, individual virtues throughout life. ${ }^{8}$ Micromorality is reflected in Gilligan's care-oriented view of moral development, ${ }^{5}$ and some of the items in MDSP do reflect caring values like community, consideration, kindness, and communication.

Construct validity of the instrument was further supported by the fact that only a small proportion (13.5\%) of the respondents older than 20 years of age reached a high total score $(\geq 24)$ on the items that represent the postconventional moral level, which is in line with the underlying theory of MDSP. 2,3

MDSP has been developed in the Scandinavian cultural context. But that does not mean that it could not be used in other countries. The content should probably be understandable in most modern societies. But if MDSP is translated into other languages, it has to be tested again with respect to reliability and validity. ${ }^{11}$ This is an interesting issue for further research.

Further development of the instrument could also include construction of new items on the postconventional level in 
order to try to enhance construct validity. In order to make MDSP possible to use among, for example, pupils and younger students, including new items on the preconventional level would be valuable. The instrument will be researched further, in order to measure and describe moral development in different groups of professionals and students and, also, to relate the measures to behavior and aspects of personality.

In conclusion, the results of this study show that the MDSP is an instrument that shows a high degree of construct validity with close correspondence to its theoretical base.

\section{Disclosure}

The authors have no conflicts of interest to delcare in relation to this work.

\section{References}

1. Jorgensen G. Kohlberg and Gilligan: duet or duel? J Moral Educ. 2006;5:179-196.

2. Kohlberg L. Moral stages and moralisation. The cognitive-developmental approach. In: Lickona T, editor. Moral Development and Behaviour: Theory, Research and Social issues. New York: Holt, Rinehart and Winston; 1976;31-53.

3. Kohlberg L. The Psychology of Moral Development. The Nature and Validity of Moral Stages. San Francisco, CA: Harper \& Row; 1984.

4. Arnold ML. Stage, sequence, and sequels: changing conceptions of morality, post-Kohlberg. Educ Psychol Rev. 2000;12:365-383.

5. Gilligan C. In a Different Voice: Psychological Theory and Women's Development. Cambridge, MA, and London: Harvard University Press; 1993.

6. Branch Jr WT. Supporting the moral development of medical students. J Gen Int Med. 2000;15:503-508.

7. Turiel E. Thoughts, emotions and social interactional processes in moral development. In: Killen M, Smetana JG, editors. Handbook of Moral Development. Mahway, NJ: Taylor and Francis e-Library.
8. Rest J, Narvaez D, Bebeau MJ, Thoma SJ. Post-Conventional Moral Thinking. A Neo-Kohlbergian Approach. Mahwah, NJ: Lawrence Erlbaum.

9. Skisland A, Bjørnestad JO, Söderhamn O. Construction and testing of The Moral Development Scale for Professionals (MDSP). Nurse Educ Today. 2011. In press.

10. Kohlberg L, Power C. Moral development, religious thinking, and the question of a seventh stage. Zygon. 1981;16:203-259.

11. Streiner DL, Norman GR. Health Measurement Scales: A Practical Guide to Their Development and Use. 3rd ed. Oxford: Oxford University Press; 2003.

12. Jöreskog KG. Estimating and testing of simplex models. British Journal of Mathematics and Statistical Psychology. 1979;23: 121-145.

13. Muthén LK, Muthén BO. Mplus: The Comprehensive Modelling Program for Applied Researchers. User's Guide. 3rd ed. Los Angeles, CA: Muthén \& Muthén; 2004.

14. Gustafsson J-E, Stahl PA. STREAMS User's Guide, Version 3.0.0. Mölndal: MultivariateWare HB; 2005.

15. Brown MW, Cudeck R. Alternative ways of assessing model fit. In: Bollen KA, Long JS, editors. Testing Structural Equation Models. Newbury Park, CA: Sage; 1993:136-162.

16. Cronbach LJ. Coefficient alpha and the internal structure of tests. Psykometrika. 1951;16:297-334.

17. Beauchamp TL, Childress JF. Principles of Biomedical Ethics. 6th ed. Oxford: Oxford University Press; 2009.

18. WMA. Ethical principles for medical research involving human subjects. Tokyo: World Medical Association Declaration of Helsinki, 2008. http://www.wma.net/en/30publications/10policies/b3/index.html Accessed May 3, 2011.

19. Dawson TL. New tools, new insights: Kohlberg's moral judgement stages revisited. International Journal of Behavioural Development. 2002;26:154-166.

20. Rest JR. DIT. Defining Issues Test. University of Minnesota, Minneapolis. http://www.mc.vanderbilt.edu/medschool/organizations/ oig/documents/.

21. Auvinen J, Suominen T, Leino-Kilpi H, Helkama K. The development of moral judgement during nursing education in Finland. Nurse Educ Today. 2004;24:538-546.
Journal of Multidisciplinary Healthcare

\section{Publish your work in this journal}

The Journal of Multidisciplinary Healthcare is an international, peerreviewed open-access journal that aims to represent and publish research in healthcare areas delivered by practitioners of different disciplines. This includes studies and reviews conducted by multidisciplinary teams as well as research which evaluates the results or conduct of such teams or

\section{Dovepress}

healthcare processes in general. The journal covers a wide range of areas and welcomes submission from practitioners at all levels, from all over the world. The manuscript management system is completely online and includes a very quick and fair peer-review system. Visit http://www.dovepress.com/testimonials.php to read real quotes from published authors. 